\title{
Quantitative prenatal growth of the cervical sympathetic trunk components in sheep (Ovis arise) during the foetal period
}

\author{
S. Bamohabat ${ }^{1}$, J. Nourinezhad ${ }^{2}$, Y. Mazaheri ${ }^{2}$ \\ ${ }^{1}$ PhD Graduated Student of Anatomy and Embryology, Department of Basic Sciences, Faculty of Veterinary Medicine, \\ Shahid Chamran University of Ahvaz, Iran \\ 2Division of Anatomy and Embryology, Department of Basic Sciences, Faculty of Veterinary Medicine, Shahid Chamran \\ University of Ahvaz, Iran
}

[Received: 17 September 2017; Accepted: 27 November 2017]

Background: Six liner measurements of constant cranial cervical ganglion (CCG), three inconstant main, first, second middle cervical ganglia (MG, MG1, MG2), and interganglionic branch (IGB) were taken to determine normal foetal growth rates and patterns of cervical sympathetic trunk (CST) components in different gestational ages.

Materials and methods: Forty sheep foetuses of both sexes aged from 60 to 140 days were divided into four groups and 80 sides of foetuses were examined under a stereomicroscope using a digital calliper.

Results: Following findings were obtained: 1) There was no significant difference for the values between sex and body side among all age groups, although sex and laterality differences in CST length and laterality differences in IGB total length and MG1 width were found regardless of age groups. 2) Correlations between dimensions of CST components and crown-rump length (CRL) were always positive during foetal period and decreased with increasing foetal age. 3) The highest growth rate in CST components in foetal sheep took place in the youngest age group because of rapid growth rates in lengths of IGB and CCG.

Conclusions: Based on these detailed findings, comparative prenatal growth rates and patterns of animal organs and body, embryological and histological data as well as neurovertebral relationships among cervical parts of sympathetic trunk, spinal cord, and vertebral column were discussed and compared with previous studies. Although allometric growth of CST in relation to CRL was constant between foetal sheep and pig, there were specific characteristics in prenatal growth of CST components in foetal sheep which were different from those of foetal pig. It seems that only growth pattern in length of CST in sheep during foetal period follows the same growth pattern of CRL, body weight, and length of cervical parts of spinal cord and vertebral column. (Folia Morphol 2018; 77, 3: 456-463)

Key words: development, growth, prenatal period, sheep, sympathetic trunk

Address for correspondence: Dr. J. Nourinezhad, Division of Anatomy and Embryology, Department of Basic Sciences, Faculty of Veterinary Medicine, Shahid Chamran University of Ahvaz, Iran, fax: +98-61-33260807, e-mail: j.nourinezhad@scu.ac.ir 


\section{INTRODUCTION}

Analyses of organ growth rates during prenatal development have brought to light definite growth tendencies and patterns and such a growth of one part of the body often appears to be quit out of step with the growth of another part, or of the organism as whole. Among organs, morphometrical changes of sympathetic trunk components during various growth phases of animals and humans foetuses have been neglected in developmental research because of its complex morphology, although our previous studies of sympathetic trunk and paravertebral ganglia have been conducted to clarify further knowledge about their detailed morphological architectures in adult dromedary camel, and bovine $[9,10]$ or developmental anatomy in sheep during foetal period $[8,11]$. These studies indicate significant variations were present between animals and humans and their variations explained in terms of comparative anatomy, embryonic development, and evolutionary changes. To better understand of these perspectives of sympathetic trunk components, it is also essential to investigate its foetal morphometric development pattern and to evaluate its relative growth rate with that of related structures such as spinal cord, and vertebral column.

For long anatomical history, only partial investigation on cervical ganglia in pig during foetal period appeared in the literature, reported by Pospieszny and Bruzewicz [12]. Ovine foetus is of critical importance for biomedical research prenatal because of its size and developmental rate which are close to that of human foetus $[2,7]$. Therefore, the aim of the present study was to examine qualitatively developmental pattern and growth of foetal cervical sympathetic trunk (CST) components in different gestational ages of sheep to determine: 1) the normal developmental values of morphometric parameters of CST components among age groups, 2) the influence of sex and body side on value of measured parameters, and 3) the normal relative growth rate of CST components in relation to crown-rump length (CRL) of the foetus.

\section{MATERIALS AND METHODS}

Forty sheep foetuses of both sexes from 40 uteri without macroscopically visible or other gross internal and external abnormality were collected from a local abattoir. None of the foetuses was a twin. Ante-mortem inspection was performed by veterinary officers and all ewes were apparently normal. The foetuses were divided into four groups (Table 1); according to their CRL [6]. The procedures and animals used had approval from the Local Ethical Committee.

Constant cranial cervical ganglion (CCG) and three inconstant MG, MG1, MG2 and their interganglionic branch (IGB), as described by Nourinezhad et al. [11], of $10 \%$ formalin fixed foetuses were measured under a stereomicroscope (Nikon, SMZ800, Japan) using a digital calliper (150 mm Mitutoyo, Japan) to an accuracy of $0.05 \mathrm{~mm}$ by a single researcher (the first author) and three times as follows: 1) The highest length (craniocaudal), width (dorsoventral), and thickness (mediolateral) of the ganglia. 2) The length (craniocaudal) of each IGB was measured. Then the total length of IGBs was calculated by adding the length values of them. 3) The CST length was determined by adding the length values of IGB total length and the length of ganglia (Fig. 1).4) The CST width was measured at the level of C6 vertebra. 5) The growth rate (in $\mathrm{mm} / \mathrm{mm}$ ) of CST length was calculated by dividing the total length of CST to CRL $\times 100$.

\section{Statistical analysis}

According to the age group, sex, and side of the body, parametric values were analysed using descriptive and analytical statistics in SPSS 16.0 and were expressed as mean \pm standard deviation, minimum/maximum, and coefficient of variation (CV). All results were evaluated by applying univariate analysis of variance for comparing the data of each dependent factor among

Table 1. The values of crown-rump lengths with regard to age groups and sexes in sheep foetuses

\begin{tabular}{|c|c|c|c|c|c|c|c|c|}
\hline \multirow[t]{2}{*}{ Age group } & \multirow{2}{*}{$\begin{array}{c}\text { Foetal age } \\
\text { Days } \\
\end{array}$} & \multicolumn{4}{|c|}{ Crown-rump length [mm] } & \multirow[t]{2}{*}{ Number } & \multicolumn{2}{|c|}{ Sex } \\
\hline & & Mean & SD & Max & Min & & Male & Female \\
\hline 1 & $60-80$ & $149.95^{\mathrm{A}}$ & 31.23 & 197 & 100 & 10 & 5 & 5 \\
\hline 2 & $80-100$ & $255^{\mathrm{B}}$ & 33.40 & 306 & 204 & 10 & 6 & 4 \\
\hline 3 & $100-120$ & $341.7^{C}$ & 22.08 & 380 & 313 & 10 & 5 & 5 \\
\hline 4 & $120-140$ & $439^{D}$ & 28.56 & 486 & 400 & 10 & 7 & 3 \\
\hline Total & $60-140$ & - & - & - & - & 40 & 23 & 17 \\
\hline
\end{tabular}

$\mathrm{P}<0.05$, difference among all age groups; $\mathrm{SD}$ — standard deviation; Min — minimum; Max — maximum; $\mathrm{A}, \mathrm{B}, \mathrm{C}, \mathrm{D}$ - different letters show significant differences in lenght among the different age groups 


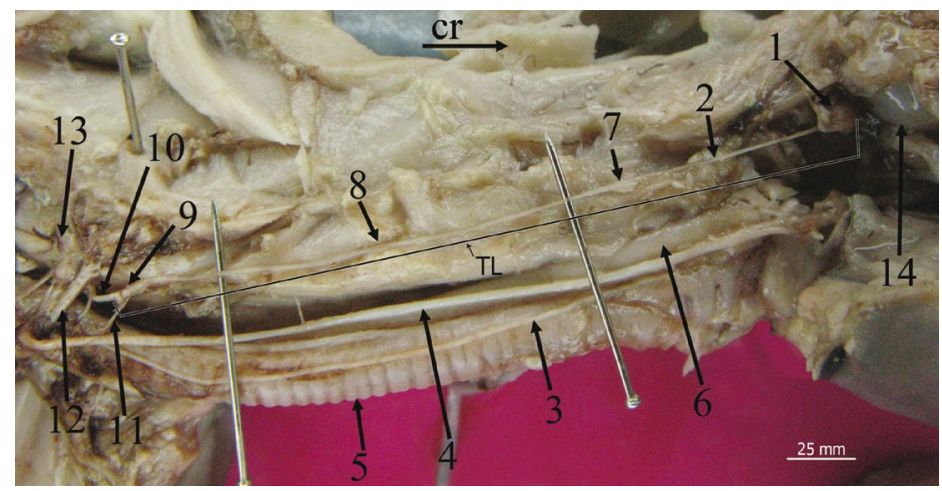

Figure 1. The measurement of total length of cervical sympathetic trunk (CST) (TL) and presence of cervical ganglia at age group 3 of male sheep foetus. The CST has been separated from vagus nerve and displaced dorsally. Right and lateral view: 1 - cranial cervical ganglion; 2 - CST; 3 - vagus nerve; 4 - common carotid artery; 5 - trachea; 6 - oesophagus; 7, 8, 9 second (MG2), first (MG1), main (MG) middle cervical ganglia; 10,11 - cranial and caudal limb of ansa subclavia; 12 - costocervical trunk; 13 - cervicothoracic ganglion; 14 - tympanic bulla; $\mathrm{Cr}$ - cranial. Scale bar (pin) $=25 \mathrm{~mm}$.

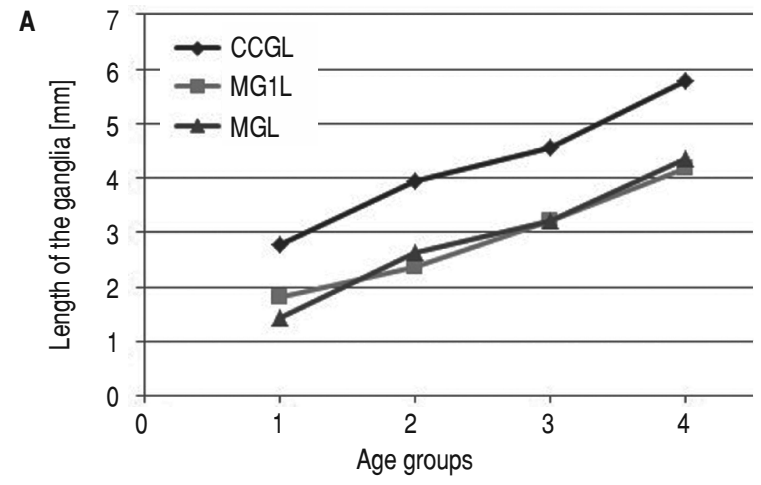

B
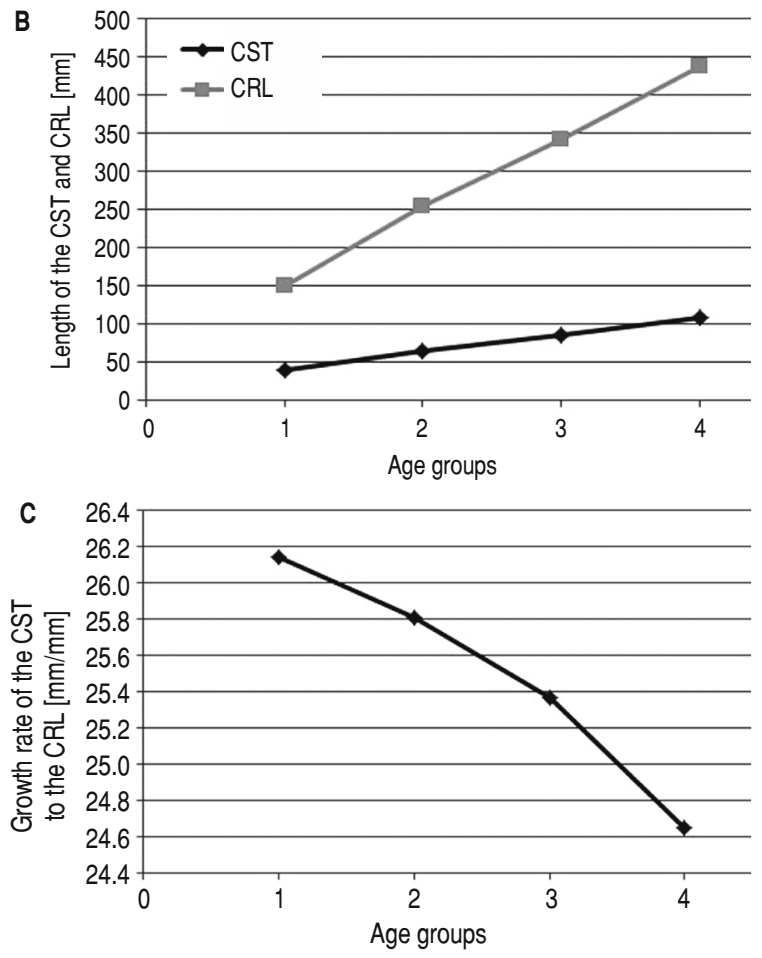

Figure 2. Variations in length of cranial cervical ganglion (CCG), first (MG1) and main (MG) middle cervical ganglia (A), cervical sympathetic trunk (CST) and crown-rump length (CRL) (B), growth rate of CST to CRL (C) in sheep of different age groups.

age groups. The significance level was accepted at $p<0.05$. Pearson's correlation coefficient $(r)$ between the dimensions of CST components and CRL was calculated for age groups combined and for each group separately. Accordingly, their $\mathrm{p}$ values were calculated.

\section{RESULTS}

According to Table 1 and Figure 2B, the mean values of CRL differed and increased significantly among all age groups, although the highest growth of CRL was noted in the youngest age group (60 to 80 days).

Many parametric values differed significantly among age groups except some dimensions of the variables within some certain age groups (Tables 2,3 )

There was no significant difference between body side and sex in any parameters among all age groups. However, there were sex and laterality differences in CST length and laterality differences in IGB total length and MG1 width regardless of age groups ( $p<0.05$, Table 4$)$.

There were positive correlations between the dimensions of CST components and CRL. However, significant correlations between the variables and CRL for each group and for age groups combined were noted $(p<0.05)$.

There were significant positive correlations between the examined parameters and CRL for age groups combined $(p<0.05)$ except the dimensions for body sides and for male MG2 as well as the width of female MG2.

CCG (Table 2, Fig. 2A): Its values revealed significant differences among groups except between age groups 3 and 4 for its width; between age groups 2 and 3 and between age groups 3 and 4 for its thickness. The highest and lowest CV belonged to the length in age group 1 and the width in age group 2, respectively. There was a strong significant correlation between CRL and CCG length in age group 1 and the width of CCG in age groups 1 and 2 .

MG (Table 3, Fig. 2A): Its values revealed significant differences among groups except between age groups 
Table 2. The values of cranial cervical ganglion (CCG), cervical sympathetic trunk (CST), and interganglionic branches (IGB) in sheep foetus

\begin{tabular}{|c|c|c|c|c|c|c|c|}
\hline Age group & Variable & Mean \pm SD [mm] & $\operatorname{Max}[\mathrm{mm}]$ & Min [mm] & CV & $r$ & $\%$ \\
\hline \multicolumn{8}{|l|}{ CCG } \\
\hline \multirow[t]{3}{*}{1} & $\mathrm{~L}$ & $2.79 \pm 0.77^{\mathrm{A}}$ & 4.58 & 1.78 & 0.27 & 0.80 & 100 \\
\hline & W & $1.74 \pm 0.39^{\mathrm{E}}$ & 2.18 & 0.95 & 0.22 & 0.74 & 100 \\
\hline & $T$ & $1.30 \pm 0.19^{1}$ & 1.63 & 0.97 & 0.15 & 0.54 & 100 \\
\hline \multirow[t]{3}{*}{2} & L & $3.94 \pm 0.52^{\mathrm{B}}$ & 5.07 & 3.07 & 0.13 & 0.31 & 100 \\
\hline & W & $2.51 \pm 0.37^{F}$ & 3.04 & 1.89 & 0.14 & 0.80 & 100 \\
\hline & $\mathrm{T}$ & $1.89 \pm 0.35^{\mathrm{J}}$ & 2.66 & 1.38 & 0.18 & 0.61 & 100 \\
\hline \multirow[t]{3}{*}{3} & L & $4.72 \pm 0.82^{C}$ & 6.33 & 3.15 & 0.17 & 0.57 & 100 \\
\hline & W & $3.13 \pm 0.35^{\mathrm{G}}$ & 3.67 & 2.51 & 0.11 & 0.17 & 100 \\
\hline & $\mathrm{T}$ & $2.17 \pm 0.44^{J K}$ & 2.77 & 1.01 & 0.20 & 0.36 & 100 \\
\hline \multirow[t]{3}{*}{4} & $\mathrm{~L}$ & $5.79 \pm 1.15^{D}$ & 9.62 & 4.16 & 0.19 & 0.14 & 100 \\
\hline & W & $3.28 \pm 0.55^{\mathrm{G}}$ & 3.98 & 1.42 & 0.16 & 0.21 & 100 \\
\hline & $\mathrm{T}$ & $2.23 \pm 0.31^{\mathrm{K}}$ & 2.81 & 1.73 & 0.14 & 0.23 & 100 \\
\hline \multicolumn{8}{|l|}{ CST } \\
\hline \multirow[t]{2}{*}{1} & L & $39.92 \pm 8.18^{A}$ & 51.35 & 24.93 & 0.20 & 0.85 & 100 \\
\hline & W & $0.31 \pm 0.08^{\mathrm{E}}$ & 0.46 & 0.2 & 0.25 & 0.64 & 100 \\
\hline \multirow[t]{2}{*}{2} & $L$ & $66.27 \pm 10.09^{B}$ & 83.41 & 51.54 & 0.15 & 0.91 & 100 \\
\hline & W & $0.45 \pm 0.10^{F}$ & 0.8 & 0.3 & 0.24 & 0.24 & 100 \\
\hline \multirow[t]{2}{*}{3} & $\mathrm{~L}$ & $84.75 \pm 7.24^{C}$ & 96.47 & 68.18 & 0.08 & 0.49 & 100 \\
\hline & W & $0.53 \pm 0.09 F$ & 0.67 & 0.4 & 0.17 & 0.11 & 100 \\
\hline \multirow[t]{2}{*}{4} & L & $107.28 \pm 15.80^{D}$ & 135.02 & 67.05 & 0.14 & 0.64 & 100 \\
\hline & W & $0.76 \pm 0.11^{G}$ & 1.1 & 0.58 & 0.15 & 0.53 & 100 \\
\hline \multicolumn{8}{|l|}{ IGB } \\
\hline 1 & L & $34.66 \pm 7.63^{\mathrm{A}}$ & 45.95 & 20.44 & 0.22 & 0.84 & 100 \\
\hline 2 & $\mathrm{~L}$ & $58.88 \pm 9.35^{\mathrm{B}}$ & 73.91 & 45.39 & 0.15 & 0.90 & 100 \\
\hline 3 & $L$ & $75.38 \pm 6.5^{C}$ & 84.5 & 61.30 & 0.08 & 0.50 & 100 \\
\hline 4 & $\mathrm{~L}$ & $95.34 \pm 14.81^{\mathrm{D}}$ & 118.5 & 56.94 & 0.15 & 0.58 & 100 \\
\hline
\end{tabular}

SD — standard deviation; Min — minimum; Max — maximum; CV — coefficient of variation; $r$ — coefficient of correlation; $L$ - length; $W$ - width; $T$ - thickness. A, B, C, D - different letters show significant differences in length among the different age groups; $E, F, G, H-$ different letters show significant differences in width among the different age groups; $\mathrm{I}, \mathrm{J}, \mathrm{K}, \mathrm{L}$ - different letters show significant differences in thickness among the different age groups; $p<0.05$

2 and 3 for its length; between age groups 1 and 2 and between age groups 2 and 3 for its width; between age groups 1 and 2, and between age groups 2 and 3 , and between age groups 3 and 4 for its thickness. The highest and lowest CV were similar to those of CCG. No strong significant correlation between MG and CRL was found in each age group.

MG1 (Table 3, Fig. 2A): Its values revealed significant differences among groups except between age groups 1 and 3 for its length; between age groups 1 and 2 and between age groups 2 and 3 for its width; between age groups 2 and 3 and between age groups 3 and 4 for its thickness. The values of width in the left side of body were $0.11 \mathrm{~mm}$ greater than that of the right side (Table 4). The highest and lowest CV belonged to the length in age group 4 and the width in age group 1, respectively. No strong significant correlation between MG1 and CRL was found in each age group.

MG2 (Table 3): Its values revealed no significant differences among groups except between age groups 1 and 3 for its length and between age groups 1 and 4 for its width. The values of thickness revealed no significant differences among all age groups. The highest and lowest CV belonged to the width in age groups 1 and 3, respectively.

IGB (Table 2): The values of its total length revealed significant differences among age groups. This value in the left side of body was $7.95 \mathrm{~mm}$ greater than that of the right side (Table 4). The highest and lowest CV belonged to age groups 1 and 3, respectively. There was a strong significant correlation between CRL and IGB in age groups 1 and 2 only.

CST (Table 2, Fig. 2B): Its values revealed significant differences among groups except between age groups 2 and 3 for its width. The CST length in the left side of body was $6.11 \mathrm{~mm}$ greater than that of the right side. The length in male foetuses was $1.32 \mathrm{~mm}$ greater than that of female foetuses (Table 4). The highest and lowest CV belonged to the width in age group 1 and length in age group 3, respectively. There was a strong 
Table 3. The values of main, first, and second middle cervical ganglia (MG, MG1, MG2) in sheep foetus

\begin{tabular}{|c|c|c|c|c|c|c|c|}
\hline Age group & Variable & Mean \pm SD [mm] & $\operatorname{Max}[\mathrm{mm}]$ & Min [mm] & CV & $r$ & $\%$ \\
\hline \multicolumn{8}{|l|}{ MG1 } \\
\hline \multirow[t]{3}{*}{1} & L & $1.44 \pm 0.33^{A}$ & 2.1 & 0.89 & 0.23 & 0.17 & 90 \\
\hline & W & $0.76 \pm 0.15^{\mathrm{E}}$ & 1 & 0.35 & 0.20 & 0.46 & 90 \\
\hline & $T$ & $0.53 \pm 0.13^{1}$ & 0.86 & 0.28 & 0.25 & 0.25 & 90 \\
\hline \multirow[t]{3}{*}{2} & $\mathrm{~L}$ & $2.64 \pm 0.96^{\mathrm{B}}$ & 4.4 & 1.45 & 0.36 & 0.63 & 75 \\
\hline & W & $0.97 \pm 0.23^{\mathrm{EF}}$ & 1.45 & 0.69 & 0.24 & 0.19 & 75 \\
\hline & $T$ & $0.66 \pm 0.08^{\mathrm{lJ}}$ & 0.81 & 0.5 & 0.12 & 0.39 & 75 \\
\hline \multirow[t]{3}{*}{3} & $\mathrm{~L}$ & $3.22 \pm 1.01^{B}$ & 4.92 & 1.63 & 0.31 & 0.23 & 85 \\
\hline & W & $1.02 \pm 0.16^{\mathrm{F}}$ & 1.3 & 0.73 & 0.15 & 0.06 & 85 \\
\hline & $\mathrm{T}$ & $0.76 \pm 0.20^{\mathrm{JK}}$ & 1.1 & 0.23 & 0.26 & 0.31 & 85 \\
\hline \multirow[t]{3}{*}{4} & $\mathrm{~L}$ & $4.36 \pm 1.07^{C}$ & 6.7 & 2.92 & 0.24 & 0.62 & 95 \\
\hline & W & $1.63 \pm 0.36^{G}$ & 2.23 & 0.99 & 0.22 & 0.03 & 95 \\
\hline & $\mathrm{T}$ & $0.83 \pm 0.25^{\mathrm{K}}$ & 1.71 & 0.52 & 0.30 & 0.06 & 95 \\
\hline \multicolumn{8}{|l|}{ MG1 } \\
\hline \multirow[t]{3}{*}{1} & L & $1.80 \pm 0.60^{A}$ & 2.9 & 0.88 & 0.33 & 0.68 & 45 \\
\hline & W & $0.61 \pm 0.22^{\mathrm{E}}$ & 0.97 & 0.32 & 0.36 & 0.68 & 45 \\
\hline & $\mathrm{T}$ & $0.48 \pm 0.15^{\prime}$ & 0.67 & 0.24 & 0.32 & 0.47 & 45 \\
\hline \multirow[t]{3}{*}{2} & L & $2.38 \pm 0.48^{A}$ & 3.18 & 1.64 & 0.20 & 0.63 & 50 \\
\hline & W & $0.89 \pm 0.17^{\mathrm{EF}}$ & 1.18 & 0.53 & 0.19 & 0.19 & 50 \\
\hline & $\mathrm{T}$ & $0.76 \pm 0.19^{J}$ & 1.03 & 0.4 & 0.25 & 0.39 & 50 \\
\hline \multirow[t]{3}{*}{3} & $\mathrm{~L}$ & $3.20 \pm 0.72^{B}$ & 4.05 & 2.28 & 0.22 & 0.36 & 45 \\
\hline & W & $0.96 \pm 0.22^{F}$ & 1.47 & 0.68 & 0.23 & 0.05 & 45 \\
\hline & $\mathrm{T}$ & $0.79 \pm 0.17^{\mathrm{JK}}$ & 1.02 & 0.58 & 0.22 & 0.18 & 45 \\
\hline \multirow[t]{3}{*}{4} & L & $4.19 \pm 0.76^{C}$ & 5.42 & 2.93 & 0.18 & 0.34 & 35 \\
\hline & W & $1.45 \pm 0.38^{G}$ & 1.99 & 0.88 & 0.26 & 0.2 & 35 \\
\hline & $\mathrm{T}$ & $1.08 \pm 0.33^{K}$ & 1.52 & 0.65 & 0.30 & 0.68 & 35 \\
\hline \multicolumn{8}{|l|}{ MG2 } \\
\hline \multirow[t]{3}{*}{1} & $\mathrm{~L}$ & $1.17 \pm 0.40^{A}$ & 1.61 & 0.8 & 0.35 & 0.78 & 15 \\
\hline & W & $0.42 \pm 0.16^{\mathrm{E}}$ & 0.61 & 0.3 & 0.39 & 0.62 & 15 \\
\hline & $\mathrm{T}$ & $0.41 \pm 0.21^{1}$ & 0.67 & 0.28 & 0.52 & 0.53 & 15 \\
\hline \multirow[t]{3}{*}{2} & $\mathrm{~L}$ & $2.68 \pm 0.44^{A B}$ & 3 & 2.37 & 0.16 & & 10 \\
\hline & W & $1.08 \pm 0.35^{\mathrm{EF}}$ & 1.33 & 0.83 & 0.32 & & 10 \\
\hline & $\mathrm{T}$ & $0.76 \pm 0.10^{\mathrm{lJ}}$ & 0.84 & 0.69 & 0.13 & & 10 \\
\hline \multirow[t]{3}{*}{3} & L & $4.56 \pm 1.87^{\mathrm{BC}}$ & 5.89 & 3.24 & 0.41 & & 10 \\
\hline & W & $1.18 \pm 0.09^{\mathrm{EFG}}$ & 1.25 & 1.11 & 0.08 & & 10 \\
\hline & $\mathrm{T}$ & $0.93 \pm 0.07^{\mathrm{IJK}}$ & 0.98 & 0.88 & 0.07 & & 10 \\
\hline \multirow[t]{3}{*}{4} & $\mathrm{~L}$ & $3.52 \pm 0.49^{\mathrm{ABC}}$ & 4.08 & 3.12 & 0.14 & & 15 \\
\hline & W & $1.34 \pm 0.41^{\mathrm{FG}}$ & 1.8 & 1 & 0.30 & & 15 \\
\hline & $\mathrm{T}$ & $1.22 \pm 0.52^{1 \mathrm{JK}}$ & 1.8 & 0.78 & 0.42 & & 15 \\
\hline
\end{tabular}

For other abbreviations see Table 2 captions.

significant correlation between CRL and CST in age groups 1 and 2 only. The growth rate of CST length in relation to CRL varied among age groups (Fig. 2C).

\section{DISCUSSION AND CONCLUSIONS}

Pospieszny and Bruzewicz [12] in pig measured only the length and width of CCG and MG length and correlated their length against CRL without using any statistical tests and presenting $p$ value for their data. They also reported that there is no perceptible influence of body side and sex on their results. In this study, there was no significant difference for the values between sex and body side among all age groups, although sex and laterality differences in CST length and laterality differences in IGB total length and MG1 width were found regardless of age groups. Although no evidence was found regarding laterality differences in the length of cervical sympathetic 
Table 4. The values of cervical sympathetic trunk (CST), interganglionic branches (IGB), and first middle cervical ganglia (MG1) in sheep foetus with regard to sex and body side

\begin{tabular}{|c|c|c|c|c|c|c|c|}
\hline Age group & Variable & Side or gender & Mean \pm standard deviation & Max & Min & $r$ & $\%$ \\
\hline \multicolumn{8}{|l|}{ CST } \\
\hline \multirow[t]{4}{*}{1} & L & Right & $37.85 \pm 8.03$ & 49.3 & 26.7 & 0.97 & 100 \\
\hline & & Left & $40.56 \pm 9.12$ & 52.67 & 28.02 & 0.94 & 100 \\
\hline & & Male & $35.63 \pm 7.42$ & 49.47 & 26.7 & 0.91 & 100 \\
\hline & & Female & $42.78 \pm 8.26$ & 52.67 & 30.93 & 0.94 & 100 \\
\hline \multirow[t]{4}{*}{2} & $L$ & Right & $63.57 \pm 9.20$ & 75.91 & 53.08 & 0.93 & 100 \\
\hline & & Left & $68.11 \pm 9.40$ & 80.95 & 55.18 & 0.95 & 100 \\
\hline & & Male & $66.86 \pm 9.71$ & 78.45 & 53.08 & 0.91 & 100 \\
\hline & & Female & $64.31 \pm 9.19$ & 80.95 & 53.25 & 0.41 & 100 \\
\hline \multirow[t]{4}{*}{3} & L & Right & $84.52 \pm 7.57$ & 93.4 & 69.38 & 0.67 & 100 \\
\hline & & Left & $88.90 \pm 4.71$ & 97.54 & 82.83 & 0.80 & 100 \\
\hline & & Male & $85.57 \pm 7.25$ & 95.03 & 69.38 & 0.55 & 100 \\
\hline & & Female & $87.86 \pm 5.89$ & 97.54 & 77.5 & 0.69 & 100 \\
\hline \multirow[t]{4}{*}{4} & L & Right & $101.84 \pm 13.08$ & 117.13 & 82.58 & 0.72 & 100 \\
\hline & & Left & $114.64 \pm 13.00$ & 141.1 & 94.68 & 0.83 & 100 \\
\hline & & Male & $104.39 \pm 12.71$ & 127.1 & 82.58 & 0.52 & 100 \\
\hline & & Female & $117.21 \pm 14.77$ & 141.1 & 95.48 & 0.70 & 100 \\
\hline \multirow[t]{4}{*}{ Total } & L & Right & $71.94 \pm 25.93^{*}$ & 117.13 & 26.7 & 0.89 & 100 \\
\hline & & Left & $78.05 \pm 29.03^{*}$ & 141.1 & 28.02 & 0.98 & 100 \\
\hline & & Male & $75.56 \pm 27.32^{*}$ & 127.1 & 26.7 & 0.96 & 100 \\
\hline & & Female & $74.24 \pm 28.19 *$ & 141.1 & 30.93 & 0.97 & 100 \\
\hline \multicolumn{8}{|l|}{ IGB } \\
\hline \multirow[t]{2}{*}{1} & $\mathrm{~L}$ & Right & $33.10 \pm 6.88$ & 41.38 & 20.44 & 0.77 & 100 \\
\hline & & Left & $36.21 \pm 8.38$ & 45.95 & 25.60 & 0.94 & 100 \\
\hline \multirow[t]{2}{*}{2} & L & Right & $56.92 \pm 9.10$ & 70.03 & 45.39 & 0.89 & 100 \\
\hline & & Left & $60.85 \pm 9.64$ & 73.91 & 48.74 & 0.96 & 100 \\
\hline \multirow[t]{2}{*}{3} & L & Right & $71.76 \pm 6.43$ & 83.86 & 61.30 & 0.56 & 100 \\
\hline & & Left & $79.00 \pm 4.34$ & 84.5 & 72.24 & 0.71 & 100 \\
\hline \multirow[t]{2}{*}{4} & L & Right & $88.58 \pm 15.52$ & 108.96 & 56.94 & 0.79 & 100 \\
\hline & & Left & $102.10 \pm 10.97$ & 118.50 & 83.83 & 0.50 & 100 \\
\hline \multirow[t]{2}{*}{ Total } & L & Right & $62.59 \pm 22.83^{*}$ & 108.96 & 20.44 & 0.95 & 100 \\
\hline & & Left & $69.54 \pm 25.86^{*}$ & 118.50 & 25.60 & 0.97 & 100 \\
\hline \multicolumn{8}{|l|}{ MG1 } \\
\hline \multirow[t]{2}{*}{1} & W & Right & $0.63 \pm 0.22$ & 0.97 & 0.32 & 0.70 & 70 \\
\hline & & Left & $0.580 \pm 0.24$ & 0.89 & 0.38 & 0.65 & 40 \\
\hline \multirow[t]{2}{*}{2} & W & Right & $0.82 \pm 0.22$ & 1.07 & 0.53 & 0.43 & 40 \\
\hline & & Left & $0.93 \pm 0.14$ & 1.18 & 0.8 & 0.35 & 60 \\
\hline \multirow[t]{2}{*}{3} & W & Right & $0.84 \pm 0.13$ & 0.95 & 0.68 & 0.83 & 50 \\
\hline & & Left & $1.12 \pm 0.23$ & 1.47 & 1 & 0.93 & 40 \\
\hline \multirow[t]{2}{*}{4} & W & Right & $1.43 \pm 0.38$ & 1.73 & 0.88 & 0.47 & 40 \\
\hline & & Left & $1.49 \pm 0.46$ & 1.99 & 1.07 & 0 & 30 \\
\hline \multirow[t]{2}{*}{ Total } & W & Right & $0.83 \pm 0.47^{*}$ & 1.73 & 0.32 & 0.70 & 50 \\
\hline & & Left & $0.99 \pm 0.38^{*}$ & 1.99 & 0.38 & 0.80 & 42 \\
\hline
\end{tabular}

${ }^{*}$ Asterisk shows significant difference between right and left or between male and female $(p<0.05)$. For abbreviations see Table 2 captions.

trunk in domestic animals [3], the explanation for the emergence of asymmetry in CST length between body sides may rest on asymmetry of aortic arches and nerves in the head during embryonic development of domestic animals. During elongation of the head and thorax and caudal shift in cardiac position of domestic animals, the left recurrent laryngeal nerve shifts more caudally than the right one [6]. Such an asymmetrical transposition and a close attachment of cervical parts of sympathetic trunk and vagus nerve can result in caudal movement of CST and its elongation on the left side in foetal sheep.

In the present investigation, the values of all variables increased with increasing foetal age, although 
CCG length, IGB total length, and CST length always differed significantly among all age groups $(p<0.05)$. Pospieszny and Bruzewicz [12] documented the values of all variables increased with increasing foetal age, but they did not mention any significant differences for parametric values. In addition, our statistical analysis indicated that the difference in length was more significant than that in width and thickness.

CCG: The length CCG in pig foetus $(3.03 \mathrm{~mm}$, $4.21 \mathrm{~mm}, 7.15 \mathrm{~mm}$ for age groups $1,2,3$, respectively) was only a few millimetres greater than that of sheep foetus in different age groups. The CCG width in sheep foetus was more similar to that of pig foetus in the youngest age group $(1.4 \mathrm{~mm})$, while with increasing foetal age CCG width in foetal pig $(2.62 \mathrm{~mm}, 3.67 \mathrm{~mm}$ for age groups 1,2 , respectively) tended to be slightly greater than that of foetal sheep.

Pospieszny and Bruzewicz [12] concluded that the correlation of CCG length and CRL for each group of foetal pig was close to zero or even negative in the youngest age groups, average in the middle age group or highest in the oldest age group of foetal pig. On the contrary, in the present study, there was a positive correlation between CRL and CCG length and the highest rate of correlation belonged to age group 1 . As a result, the correlation between them in the youngest foetal stage was negative in foetal pig, whereas such a correlation was always positive in foetal sheep.

MG: Its length in foetal sheep in different age groups was similar to that of pig foetus $(2.23 \mathrm{~mm}$, $2.11 \mathrm{~mm}, 4.22 \mathrm{~mm}$ ) for the age groups $1,2,3$, respectively [12]. No correlation between MG length and CRL was noted in foetal pig, which is not in line with the present findings.

Neurovertebral growth relationships among cervical parts of sympathetic trunk, spinal cord and vertebral column have not been paid any attention yet, although bilateral 8 embryonic sympathetic ganglia and trunk are located along the length of vertebral column, level with the body of each vertebra and are connected segmentally by grey communicating branches to ventral branch of spinal nerve [6]. Ghazi and Gholami [4] studied the growth changes of length of cervical parts of spinal cord and vertebral column in sheep from 60 to 150 days (divided into three age groups) and described the lengths of cervical parts of spinal cord/vertebral column were $50.10 / 50.17 \mathrm{~mm}$, $72.58 / 68.42 \mathrm{~mm}$, and $98.00 / 91.67 \mathrm{~mm}$ in 3, 4, 5 month foetus, respectively and increased significantly. They also concluded that cervical parts of spinal cord and vertebral column in foetal sheep in all age groups grew more or less with the same pace. In the present study, CST lengths were $39.21 \mathrm{~mm}, 65.84 \mathrm{~mm}, 86.71 \mathrm{~mm}$, and $108.24 \mathrm{~mm}$ in age groups $1,2,3,4$, respectively and increased significantly. By comparing the result of this investigation with those reported above, it can be concluded that although the length of cervical parts of spinal cord, sympathetic trunk, and vertebral column in foetal sheep increased with advancing foetal age, the CST was relatively more advanced in growth of length throughout foetal period than corresponding spinal cord and vertebral column.

Embryological accounts also seem to support the above conclusion. The initiation of neural crest cells' immigration is related, both spatially and temporally, to the formation of neural tube and somites. In general, this process occurred as a rostrocaudal wave; however, the exact starting point of neural crest cells seems to be species-specific and can begin before, during or after neural tube formation [5]. Moreover, the actual formation of sympathetic ganglia takes place in rather early stages of development of embryo before spinal nerves start growing out [1]. Hence, it can be hypothesis that cervical parts of spinal cord-vertebral column length is relatively passive in the differentiate process in comparison with the corresponding sympathetic trunk length. Such an elongation of CST may produce lengthening and obliquity of grey communicating branch of CCG during foetal period and relative displacement of either caudal or cranial cervical ganglia. According to our previous publications, the caudal and cranial cervical ganglia tended to be located at the level of the first rib to fuse with the first one or two thoracic ganglia, forming cervicothoracic ganglion and at the level of cranial base in foetal sheep, respectively [8-10], although 8 embryonic cervical ganglia were located at the level of each vertebra [13]. However, detailed embryological and molecular investigations are needed on abovementioned hypothesis.

In this study, the relative growth in the length of CST (dimensions of all components) in relation to CRL was negatively allometric during foetal period, similar to the findings on the relative growth length of CCG in relation to CRL in foetal pig [12] and the relative growth length of cervical parts of spinal cord and vertebral column to the total length of vertebral column in sheep [4].

On the other hand, the most striking finding of the present study is related to comparative foetal growth rates of CST length between sheep and pig during 
foetal period. In the present study, the relative growth rate of CST length in relation to CRL declined with increasing foetal age, which corresponded with findings of cervical spinal cord in relation to the total length of vertebral column in foetal sheep [4]. On the contrary, Pospieszny and Bruzewicz [12] documented that relative growth rate of CCG length in relation to CRL of foetal pig increased with increasing foetal age. Therefore, the highest growth rate in the length of CST and cervical part of spinal cord in foetal sheep was in the youngest foetal age, whereas the greatest growth rate of CCG length in foetal pig was in the oldest foetal stage.

To shed light on this difference, it is essential to explore the previous recorded data on the comparative parental growth rates and patterns of body tissues between sheep and pig during foetal period because the rapidity of growth of organs and even the growth of some parts of an organ are quite different in various animals at corresponding foetal period [6]. In this point of view, findings of following previous data support our results. Sivachelvan et al. [13] expounded that the increase in relative growth of body weight to CRL in sheep was greater during the second trimester, while the absolute growth of body weight was greater during the third trimester. McGadeay et al. [6] have computed growth curve for CRL in sheep during gestational age from reviewed literature and based on their data it can be concluded that the most growth of CRL was in the second trimester of pregnancy. When converting our foetal age groups into second and third trimesters, it seems that growth pattern of CST to CRL in sheep during foetal period occurred at the same trimesters and follows the same growth pattern of body weight, and CRL.

\section{Acknowledgements}

We are thankful to Dr. Maniati from Department of English at Ahvaz Jundishapur University for editing of this manuscript, to Research Affairs of Shahid Chamran University of Ahvaz for financial support, and to Mr. Fathi for his technical assistance.

\section{REFERENCES}

1. Balinsky BI. An Introduction to Embryology. WB Saunders Company, Philadelphia 1981.

2. Frasch MG, Müller T, Wicher $C$, et al. Fetal body weight and the development of the control of the cardiovascular system in fetal sheep. J Physiol. 2007; 579(Pt 3): 893-907, doi: 10.1113/jphysiol.2006.124800, indexed in Pubmed: 17218361.

3. Getty R. Sisson and Grossman's the Anatomy of the Domestic Animals. WB Saunders Company, Philadelphia 1975.

4. Ghazi SR, Gholami S. Allometric growth of the spinal cord in relation to the vertebral column during prenatal and postnatal life in the sheep (Ovis aries). J Anat. 1994; 185(Pt 2): 427-431, indexed in Pubmed: 7961149.

5. Majewski M. Synaptogenesis and structure of the autonomic ganglia. Folia Morphol. 1999; 58(3 Suppl 2): 65-99, indexed in Pubmed: 10959262.

6. McGeady TA, Quinn PJ, Fitzpatrick ES, Rayon MT. Veterinary Embryology. Blackwell Publishing, Oxford, UK 2006.

7. Morel O, Laporte-Broux B, Tarrade A, et al. The use of ruminant models in biomedical perinatal research. Theriogenology. 2012; 78(8): 1763-1773, doi: 10.1016/j.theriogenology.2012.06.012, indexed in Pubmed: 22925634.

8. Nourinezhad J, Gilanpour H, Radmehr B. Prenatal development of the fetal thoracic sympathetic trunk in sheep (Ovis aries). Auton Neurosci. 2013; 177(2): 154-162, doi: 10.1016/j.autneu.2013.03.013, indexed in Pubmed: 23639816

9. Nourinezhad J, Mazaheri Y, Biglari Z. Detailed anatomy of the cranial cervical ganglion in the dromedary camel (Camelus dromedarius). Anat Rec (Hoboken). 2015; 298(8): 1479-1491, doi: 10.1002/ar.23169, indexed in Pubmed: 25950508 .

10. Nourinezhad J, Mazaheri Y, Saberifar S. Topography and Morphology of the Bovine Cranial Cervical Ganglion and its Branches. Int J Morphol. 2016; 34(2): 545-556, doi: 10.4067/s0717-95022016000200022.

11. Nourinezhad J, Bamohabat S, Mazaheri Y. Developmental morphology and topography of the components of the cervical sympathetic trunk in sheep (ovis aries) during the fetal period. Anat Rec (Hoboken). 2017; 300(12): 2250-2262, doi: 10.1002/ar.23683, indexed in Pubmed: 28865185.

12. Pospieszny N, Bruzewicz S. Morphology and development of the cervical part of the sympathetic trunk (pars cervicalis trunci sympathici) in the pig (Sus scrofa L.) during the prenatal period. Ann Anat. 1998; 180(4): 353-359, indexed in Pubmed: 9728278.

13. Sivachelvan MN, Ghali Ali M, Chibuzo GA. Foetal age estimation in sheep and goats. Small Rum Res. 1996; 19(1): 69-76, doi: 10.1016/0921-4488(95)00709-1. 